\title{
Identification of the mechanisms responsible for anomalies in the tropical lower thermosphere/ionosphere caused by the January 2009 sudden stratospheric warming
}

\author{
Maxim V. Klimenko ${ }^{1, *}$, Vladimir V. Klimenko ${ }^{1}$, Fedor S. Bessarab ${ }^{1,2}$, Timofei V. Sukhodolov ${ }^{1,3,4}$, \\ Pavel A. Vasilev ${ }^{1,2}$, Ivan V. Karpov ${ }^{1,2}$, Yurij N. Korenkov ${ }^{1}$, Irina E. Zakharenkova ${ }^{1}$, \\ Bernd Funke ${ }^{5}$, and Eugene V. Rozanov ${ }^{1,3,4}$ \\ ${ }^{1}$ West Department of Pushkov Institute of Terrestrial Magnetism, Ionosphere and Radio Wave Propagation, Russian Academy of Sciences, \\ 236017 Kaliningrad, Russia \\ ${ }^{2}$ Immanuel Kant Baltic Federal University, 236041 Kaliningrad, Russia \\ 3 Physikalisch-Meteorologisches Observatorium, World Radiation Center, 7260 Davos, Switzerland \\ ${ }^{4}$ Institute for Atmospheric and Climate Science, ETH Zürich, 8092 Zürich, Switzerland \\ ${ }^{5}$ Instituto de Astrofisica de Andalucia, CSIC, 18008 Granada, Spain
}

\begin{abstract}
We apply the Entire Atmosphere GLobal (EAGLE) model to investigate the upper atmosphere response to the January 2009 sudden stratospheric warming (SSW) event. The model successfully reproduces neutral temperature and total electron content (TEC) observations. Using both model and observational data, we identify a cooling in the tropical lower thermosphere caused by the SSW. This cooling affects the zonal electric field close to the equator, leading to an enhanced vertical plasma drift. We demonstrate that along with a SSW-related wind disturbance, which is the main source to form a dynamo electric field in the ionosphere, perturbations of the ionospheric conductivity also make a significant contribution to the formation of the electric field response to SSW. The post-sunset TEC enhancement and pre-sunrise electron content reduction are revealed as a response to the 2009 SSW. We show that at post-sunset hours the SSW affects low-latitude TEC via a disturbance of the meridional electric field. We also show that the phase change of the semidiurnal migrating solar tide (SW2) in the neutral wind caused by the 2009 SSW at the altitude of the dynamo electric field generation has a crucial importance for the SW2 phase change in the zonal electric field. Such changes lead to the appearance of anomalous diurnal variability of the equatorial electromagnetic plasma drift and subsequent low-latitudinal TEC disturbances in agreement with available observations.

Plain Language Summary - Entire Atmosphere GLobal model (EAGLE) interactively calculates the troposphere, stratosphere, mesosphere, thermosphere, and plasmasphere-ionosphere system states and their response to various natural and anthropogenic forcing. In this paper, we study the upper atmosphere response to the major sudden stratospheric warming that occurred in January 2009. Our results agree well with the observed evolution of the neutral temperature in the upper atmosphere and with low-latitude ionospheric disturbances over America. For the first time, we identify an SSW-related cooling in the tropical lower thermosphere that, in turn, could provide additional information for understanding the mechanisms for the generation of electric field disturbances observed at low latitudes. We show that the SSW-related vertical electromagnetic drift due to electric field disturbances is a key mechanism for interpretation of an observed anomalous diurnal development of the equatorial ionization anomaly during the 2009 SSW event. We demonstrate that the link between thermospheric winds and the ionospheric dynamo electric field during the SSW is attained through the modulation of the semidiurnal migrating solar tide.
\end{abstract}

Keywords: sudden stratospheric warming / thermospheric temperature / TEC / ionosphere / electric field / ionospheric conductivity / mesospheric tides

\footnotetext{
*Corresponding author: maksim.klimenko@mail.ru
} 


\section{Introduction}

The Earth's ionosphere is a complex system where dynamical, radiative, and chemical processes act together. Ionospheric variability is mostly controlled by solar and geomagnetic activity, but a significant part of it $(\sim 20 \%)$ is still associated with a forcing that comes from the lower and middle atmosphere (Forbes et al., 2000). Main mechanisms responsible for this connection include planetary waves, atmospheric tides, and gravity waves (Chau et al., 2012). A proper representation of these processes in models is crucial for understanding and predicting the ionospheric variability. Sudden Stratospheric Warmings (SSWs) are large meteorological events characterized by the appearance of substantial anomalies occurring throughout the atmosphere, from the troposphere to the mesosphere/lower thermosphere (MLT) region. SSW events are driven by planetary waves propagating upward from the troposphere (Butler, 2015). Wave-breaking in the stratosphere causes a deceleration or even reversal of the polar vortex resulting in a significant rise of polar temperatures. These huge and abrupt stratospheric anomalies can propagate upwards, modulating the thermosphere/ionosphere system. Several mechanisms responsible for the ionospheric response to SSWs have been proposed. Some publications (Fejer et al., 2011; Forbes \& Zhang, 2012; Pedatella et al., 2012; Yamazaki, 2014) discussed the alteration of thermospheric tides resulting in the generation of anomalous electric fields through the E-region dynamo. Pancheva \& Mukhtarov (2011) suggested a warming of the high latitude lower thermosphere during SSWs followed by changes of plasma drifts at middle and low latitudes.

To examine the validity and importance of each suggested mechanism of the upper atmosphere response to SSW events, it is necessary to perform theoretical investigations with global coupled models that include the thermosphere-ionosphere system. During the last decade, multiple attempts of such investigations have been carried out using different models based on first principles. It was discovered that SSWs generate a warming in the high latitude lower thermosphere and extra-polar mesosphere, while the high latitude mesosphere and extra-polar lower thermosphere cools (Liu \& Roble, 2002; Bessarab et al., 2012; Korenkov et al., 2012; Tan et al., 2012). The mechanism of global negative ionospheric disturbance formation during the 2008 and 2009 SSW events, proposed by Pancheva \& Mukhtarov (2011), was confirmed using the Global Selfconsistent Model of the Thermosphere, Ionosphere, Protonosphere (GSM TIP) (Bessarab et al., 2012; Korenkov et al., 2012). The crucial importance of the "fountain effect", caused by the semidiurnal variation in the upward electromagnetic plasma drift within the semidiurnal variation of the plasma density during the 2009 SSW event was discussed by Jin et al. (2012).

Despite recent progress in model development, disagreement between the modeled and observed upper atmosphere responses to SSW events still exists due to difficulties in the treatment of non-linear interactions between stationary planetary waves, atmospheric tides, and gravity waves (Pedatella et al., 2016). For example, during the January 2009 SSW event, observed morning-noon enhancements and afternoon decreases in the electron density at low latitudes (Chau et al., 2012) are much less pronounced or absent in model results (Goncharenko et al., 2010b, Jin et al., 2012; Klimenko et al., 2015; Pedatella et al., 2016). Several studies conclude that the primary mechanism responsible for total electron content (TEC) disturbances at low latitudes during the $2009 \mathrm{SSW}$ event is a perturbation of the zonal electric field (the vertical $E \times B$ plasma drift) (Goncharenko et al., 2010a; Jin et al., 2012; Pedatella et al., 2012; Klimenko et al., 2015). Recently, several authors exploited different models and simulation techniques (e.g., assimilation of data or dynamical nudging) to reproduce the observed equatorial electromagnetic drift disturbances during the 2009 SSW event (Fuller-Rowell et al., 2011a; Jin et al., 2012; Pedatella et al., 2016). However, most of these attempts were not fully successful and there are still open questions on the generation mechanism of such zonal electric field disturbances during SSW events and for the requirement of atmosphere-ionosphere system models that aim to properly simulate such processes. To answer these questions, we applied the recently developed Entire Atmosphere GLobal (EAGLE) model (Klimenko et al., 2018, 2019; Vasiliev et al., 2019) and analyzed disturbances of temperature and wind above $80 \mathrm{~km}$, the low-latitude ionospheric electric field, and the TEC during the January 2009 SSW event. The model performance was evaluated by comparing simulations with neutral temperature observed by the MIPAS/Envisat instrument and global positioning system total electron content (GPS TEC) measurements.

\section{Model and data used}

\subsection{The EAGLE model}

Historically, numerical models of the upper $(>80 \mathrm{~km})$, middle and lower $(<80 \mathrm{~km})$ parts of the atmosphere have progressed almost independently, with prescriptions of lower/upper boundary conditions that are usually a very rough approximation of all the physics happening below/above. Recent progress in measurements and models made it clear that the coupling between atmospheric layers is important and that it should be addressed explicitly. The new EAGLE model is a step in this direction as it combines the upper atmosphere model (GSM TIP) and the neutral atmosphere model (HAMMONIA [Hamburg Model of the Neutral and Ionized Atmosphere]). The chemistry-climate model HAMMONIA is based on the fifth version of the general circulation model of the atmosphere MAECHAM5 and covers the atmosphere from the ground up to $250 \mathrm{~km}$ with a horizontal resolution of $\sim 1.9^{\circ} \times 1.9^{\circ}$. For the proper description of the processes above the mesopause, the model includes radiation heating due to absorption of extreme solar UV, non-LTE treatment of the radiative cooling, molecular diffusion, ion drag, as well as simplified ion chemistry with which to treat the impact of precipitating energetic particles. The model has been described by Schmidt et al. (2006) in detail and recently underwent some improvements (Meraner \& Schmidt, 2016). To mimic any particular meteorological situations, the model can be nudged to the wind and temperature fields obtained from a reanalysis system. The state and variability of the thermosphere/ionosphere system are calculated with the GSM TIP model (Namgaladze et al., 1988; Korenkov et al., 1998; Klimenko et al., 2007). This model is based on the system of quasi-hydrodynamic equations of continuity, motion, and heat balance for neutral and charged particles of 
the cold near-Earth plasma in conjunction with the equation for the electric potential in the altitude range from $80 \mathrm{~km}$ to a geocentric distance of $\sim 15$ Earth radii. GSM TIP has $5^{\circ} \times 5^{\circ}$ horizontal resolution in a geomagnetic coordinate system. For the coupling of these EAGLE components, we programmed a coupler that prepares fields of both models for the exchange in the overlap region and allows parallel (HAMMONIA) and sequential (GSM TIP) codes to run simultaneously. GSM TIP uses wind, temperature, and neutral density fields from HAMMONIA in the 80-120 km region and returns the Joule heating and ion drag fields used by HAMMONIA in the region from $80 \mathrm{~km}$ to its top. The data exchange occurs after every dynamical time step in HAMMONIA $(3 \mathrm{~min})$. We simulated atmospheric changes during January 2009 using representative boundary conditions for both model components. The HAMMONIA module was run in nudging mode using six-hourly meteorological fields from ERA-Interim as was done in the HEPPA-2 study (Funke et al., 2017). EAGLE model runs were performed with constant solar and geomagnetic activities that were very low and stable during the considered period.

\subsection{Observational data}

\subsubsection{MIPAS data}

The Michelson Interferometer for Passive Atmospheric Sounding (MIPAS) instrument on board the ENVISAT satellite measured infrared spectral radiation from the limb allowing for retrievals of atmospheric species and temperature profiles during 2002-2012 (Fischer et al., 2008). Temperature profiles up to $170 \mathrm{~km}$ were retrieved from the $\mathrm{CO}_{2}$ and $\mathrm{NO}$ emissions measured in the upper atmosphere observation mode with an accuracy/vertical resolution of $0.5-7 \mathrm{~K} / 3-10 \mathrm{~km}$ below and 5-60 K/6-20 km above $100 \mathrm{~km}$ altitude (Bermejo-Pantaleón et al., 2011). The measurements are available for day and night conditions. During January and February 2009, the MIPAS instrument operated globally in the upper atmosphere mode for about one day out of every 10 , producing $~ 1000$ temperature profiles per day in the altitude range $42-172 \mathrm{~km}$. For this work, we exploit global observations in the upper atmosphere mode taken on January 1, 12, 19, and 20, 2009, and additional upper atmosphere observations (three orbits per day measuring over the $20^{\circ} \mathrm{W}-70^{\circ} \mathrm{E}$ and $160^{\circ} \mathrm{E}-110^{\circ} \mathrm{W}$ longitudinal bands) covering the periods from 14 to 18 January and from 21 to 27 January 2009. These data were used by Funke et al. (2010) to characterize the upper atmosphere temperature response to the January 2009 SSW event over the Polar Regions $\left(70^{\circ}-90^{\circ} \mathrm{N}\right)$. Here we use the same data to demonstrate the temperature response in the tropical upper atmosphere, which is important for understanding the ionospheric processes.

\subsubsection{GPS TEC data}

Total Electron Content (TEC) is one of the key parameters used for ionosphere monitoring and research. We calculate absolute vertical TEC values from raw GPS/GLONASS (GLObal NAvigation Satellite System) measurements using the technique described by Zakharenkova et al. (2016). We construct high-resolution TEC maps over the American region by averaging and binning all TEC values into cells of $1^{\circ}$ in geographic latitude/longitude. We analyze meridional slices constructed as TEC averages within the band of $\pm 5^{\circ}$ around the geographical longitude of $75^{\circ} \mathrm{W}$ and plotted as a function of geographic latitude and Universal Time (UT).

\section{Simulation results and comparison with observations}

The prolonged continuous minimum of solar and geomagnetic activity over 2007-2009 allows a careful examination of relationships between processes in the middle and upper atmosphere, as for this period, solar and magnetospheric sources in upper atmosphere variability were minimized (Goncharenko et al., 2010a). January 2009 presents a unique major SSW event that was very strong and long-lasting (Labitzke \& Kunze, 2009). The single record-breaking stratospheric sudden warming event started on 20 January 2009. During this dramatic SSW event, the stratospheric temperatures at $90^{\circ} \mathrm{N}$ sharply increased by more than $70 \mathrm{~K}$, while the zonal mean zonal wind at $60^{\circ} \mathrm{N}$ reversed from westerly (winter-like) to easterly (summer-like). The peak warming at the $10 \mathrm{hPa}$ level was reached together with a zonal wind reversal on 23-24 January 2009. In this section, we demonstrate the behavior of middle and upper atmosphere parameters over 12-30 January 2009 in order to present the response to this SSW event.

\subsection{Daily and zonal mean anomalies in the middle and upper atmosphere}

Anomalies of different parameters presented in this subsection were obtained as differences between current zonal mean values and a background condition. Here, we define the background condition as monthly mean values for all considered parameters.

Figure 1 demonstrates day-to-day variability of the neutral temperature anomalies at high latitudes $\left(70-90^{\circ} \mathrm{N}\right)$ in the Northern Hemisphere and in the tropics $\left(20^{\circ} \mathrm{S}-20^{\circ} \mathrm{N}\right)$ modeled with EAGLE and observed by MIPAS. In the northern high latitudes, EAGLE reproduces well the observed stratospheric warming, mesospheric cooling, lower thermospheric warming, and thermospheric cooling caused by the SSW event. These main features of SSW-related polar temperature changes have already been discussed by Liu \& Roble (2002), Funke et al. (2010) and Bessarab et al. (2012). Note that the EAGLE model results do not reproduce those observed by MIPAS for a substantial tropical thermospheric warming prior to and during the SSW event, before its temperature peak. The reason for this model/data disagreement is beyond the scope of this paper. At low-latitudes, EAGLE reproduces well the MIPAS observations of the stratospheric cooling, mesospheric warming, and lower thermospheric cooling caused by the SSW event. The tropical SSW-related stratospheric cooling, mesospheric warming, and thermospheric cooling in the tropics are visible in the TIME-GCM model results (Liu \& Roble, 2002). However, the authors of that study did not discuss or explain these features and did not emphasize that pronounced cooling covers the entire thermosphere. The cooling of the equatorial upper thermosphere during the 2009 SSW event was revealed from simulations and observations by Liu et al. $(2011,2013,2014)$. According to their results, the thermospheric cooling continuously increases 

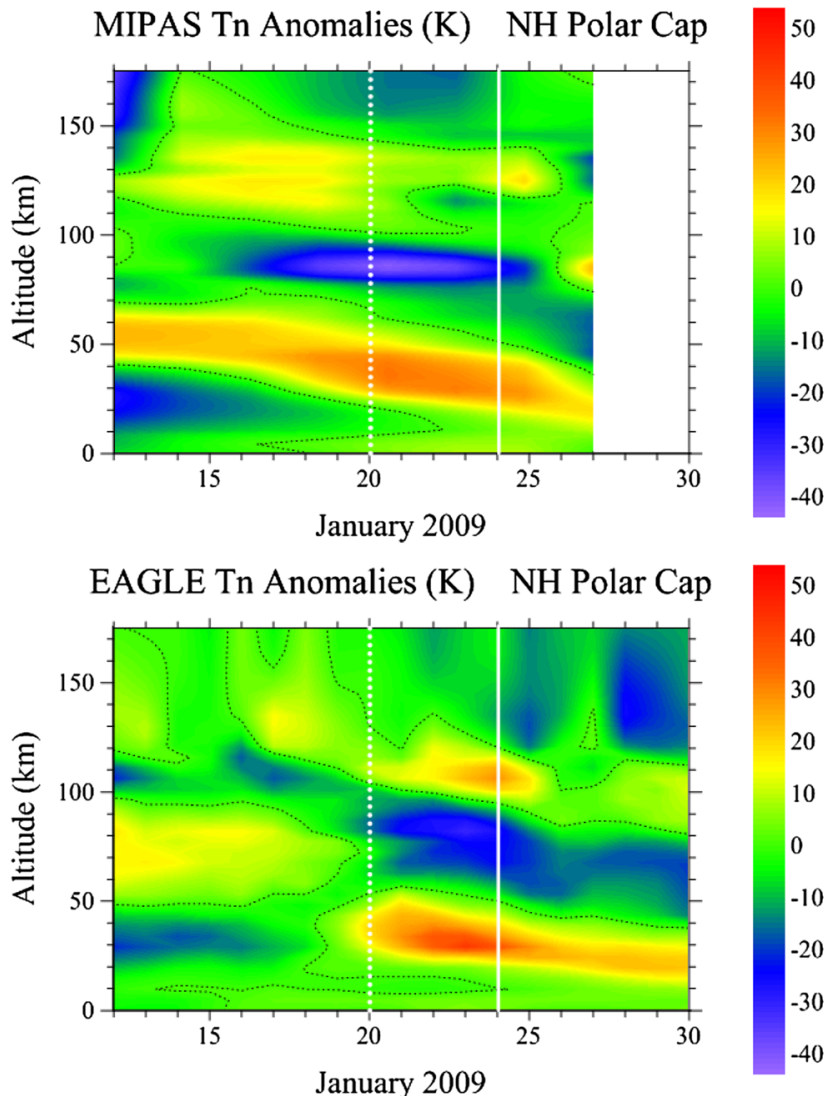
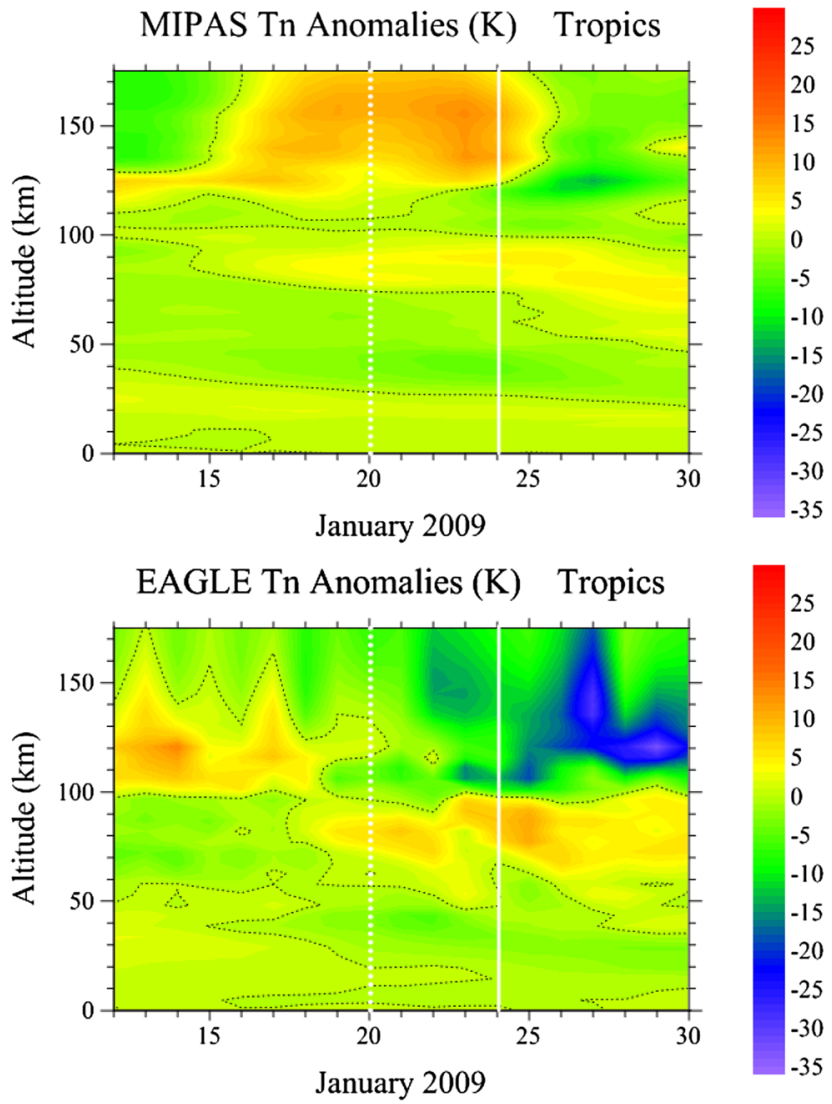

Fig. 1. Day-to-day variability of zonal mean neutral temperature anomalies during January 2009 above the northern polar cap $\left(70^{\circ}-90^{\circ} \mathrm{N}\right.$, left panels) and above the tropics $\left(20^{\circ} \mathrm{S}-20^{\circ} \mathrm{N}\right.$, right panels) obtained using MIPAS observational data (top) and EAGLE model results (bottom). Vertical lines indicate the onset (dotted) and peak (solid) of the 2009 SSW.

above $100 \mathrm{~km}$ with height, in agreement with the simulations by Liu \& Roble (2002). In contrast, Fuller-Rowell et al. (2011b), using model/data results over this period, did not find evidence at any latitude for the SSW-related decrease of upper thermospheric temperatures. They confirmed that the observed lowlatitude upper thermospheric cooling can be amply attributed to small changes in geomagnetic activity during this period.

Our model set-up excludes solar and geomagnetic control of temperature anomaly formation in the tropical stratosphere, mesosphere, and lower thermosphere during the January 2009 SSW event. The tropical mesospheric heating response encountered in our model results and in the MIPAS observations agrees well with the analysis of different independent measurements presented by Singh \& Pallamraju (2015). Our analysis of both the observational data and model results further indicates that the tropical thermospheric cooling response maximizes in the lower thermosphere. This disagrees with the Ground-to-topside model of Atmosphere and Ionosphere for Aeronomy (GAIA) results (Liu et al., 2013, 2014) that demonstrated the thermospheric cooling with a maximum in the upper tropical thermosphere as a response to the same SSW event. According to our model/data analysis, the cooling of the tropical lower thermosphere occurred (with the onset on 18 January and maximal cooling on 27 January) at the altitudes of the E region. The processes at these heights are responsible for the ionospheric dynamo electric field generation. Below, we will discuss the implications of this finding for the ionospheric equatorial electric field response to the January 2009 SSW event.

According to the modelling results of Liu et al. (2014), the zonal mean temperature above $100 \mathrm{~km}$ altitude drops at all latitudes except for a narrow, high latitude region in the Northern hemisphere. The zonal mean zonal wind experiences a strong westward perturbation in the tropical thermosphere, along with a distinct change in the meridional circulation. This change consists of two parts: a global scale north-to-south flow accompanied by the upwelling/downwelling in the northern/southern polar region and a fountain-like flow in the tropical lower thermosphere.

Figure 2 shows the simulated behavior of zonal and daily averaged temperature and horizontal winds in the lower thermosphere, and the zonal electric field and conductivities in the ionosphere at $120 \mathrm{~km}$ from 12 to 30 January 2009. As noted in the previous subsection, the lower thermosphere substantially cools during the SSW (22-25 January 2009). The tropical lower thermospheric cooling during the SSW has a latitudinal structure with two maxima near to $30^{\circ} \mathrm{S}$ and $30^{\circ} \mathrm{N}$ and the minimal cooling is close to the equator. After 25 January, the cooling of the northern tropics continues, while the southern hemisphere and equatorial area noticeably warm up with a maximum on 27 January, which is then replaced by a cooling starting from 

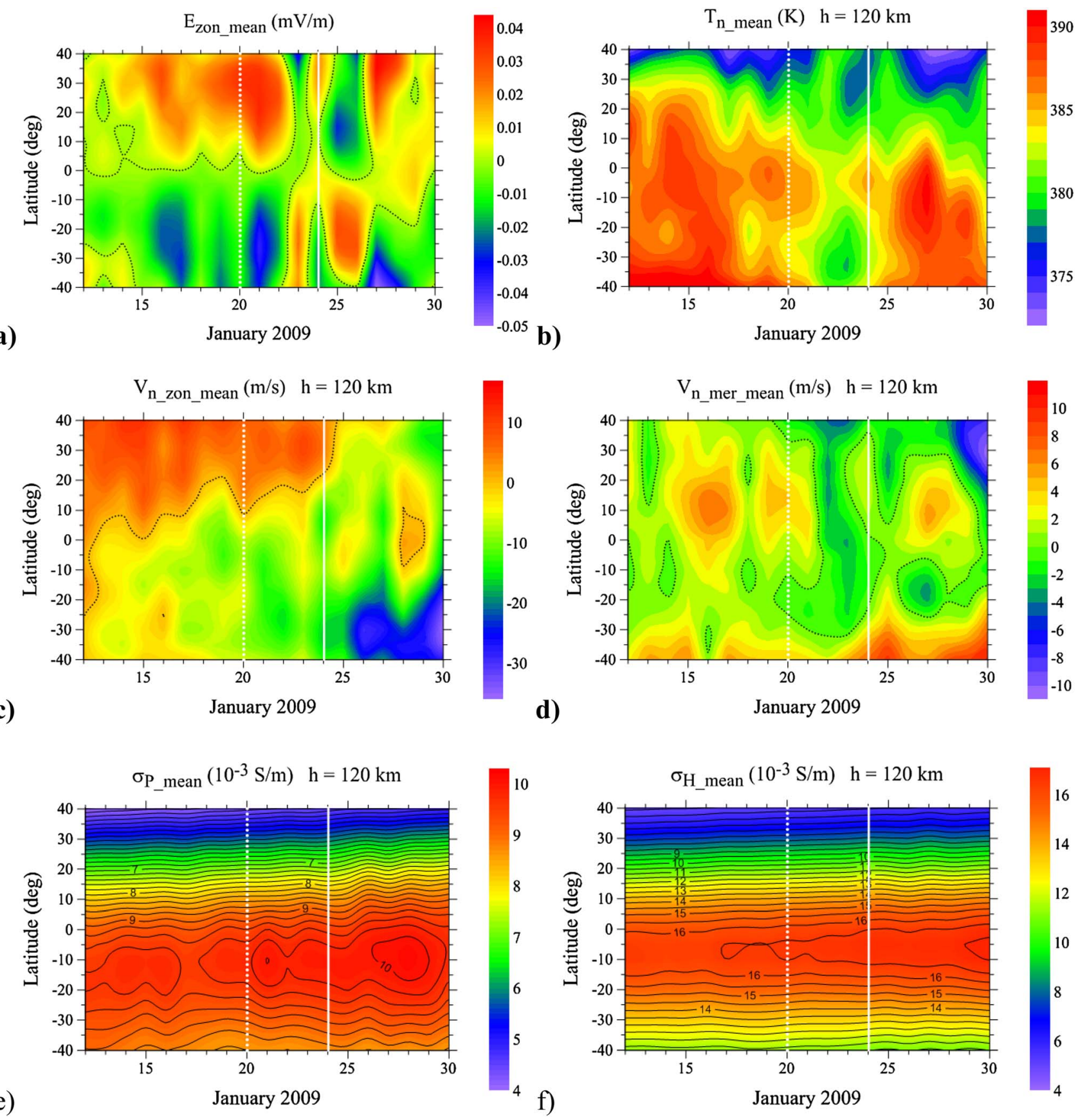

Fig. 2. EAGLE-simulated day-to-day variability of daily averaged zonal mean anomalies in (a) zonal electric field, (b) neutral temperature, (c) zonal, and (d) meridional wind velocity, (e) Pedersen, and (f) Hall conductivities at $120 \mathrm{~km}$ altitude during January 2009. Vertical lines indicate the onset (dotted) and peak (solid) of the 2009 SSW.

30 January. Formation of the anomalous latitudinal distribution of the zonal electric field during the SSW can be explained by these pronounced temperature changes in the tropical lower thermosphere. In particular, during 22-25 January, the sign of the averaged zonal electric field changes three times in both northern and southern hemispheres. On 27 January, the eastward electric field at the equator noticeably increases and extreme values of the zonal electric field are shifted poleward in comparison to other days. The simultaneous appearances of
SSW-related anomalies in the lower thermosphere and in the zonal electric field at low latitudes suggest that the changes in these two parameters are closely related. How can the temperature change in the lower thermosphere affect the electric field? The electric field near the equator is sensitive to changes in conductivity and variations in horizontal winds that are, in turn, related to the temperature change. It is visible that the two above-mentioned parameters respond to the warming. Figure 2 shows a gradual increase in the Pedersen and Hall conductivities 
TEC, TECU Jan $15,2009 \lambda=75^{\circ} \mathrm{W}$

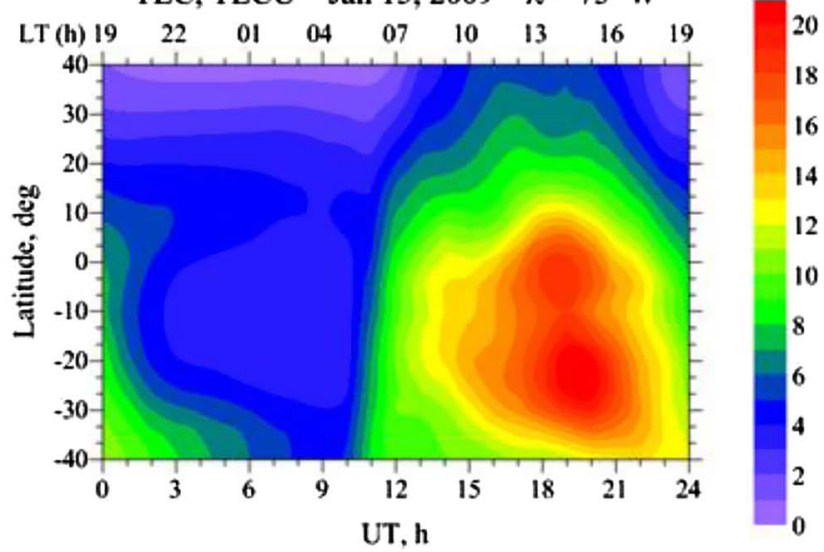

$\triangle$ TEC, TECU Jan 27 vs Jan $15\left(\lambda=75^{\circ} \mathrm{W}\right)$

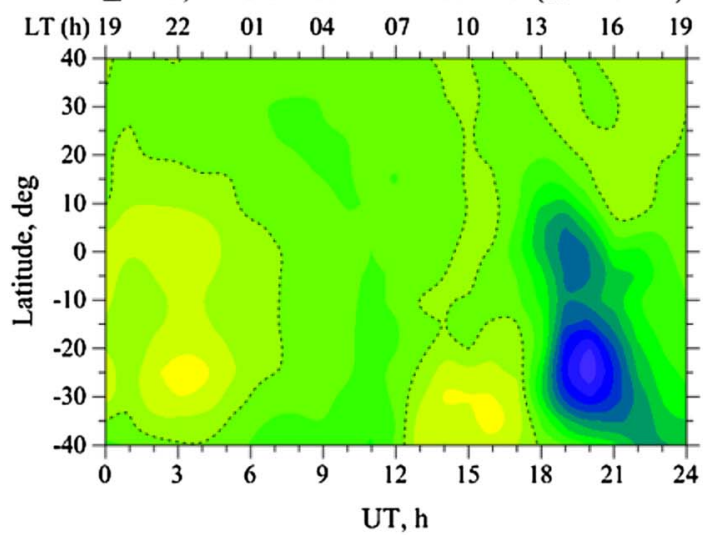

GPS TEC, TECU Jan $15,2009 \lambda=75^{\circ} \mathrm{W}$

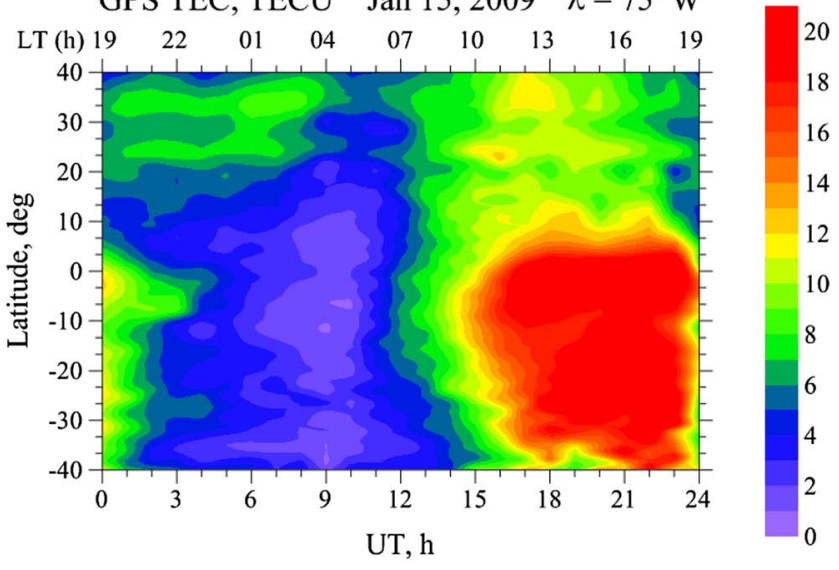

$\triangle$ GPS TEC, TECU Jan 27 vs Jan $15\left(\lambda=75^{\circ} \mathrm{W}\right)$

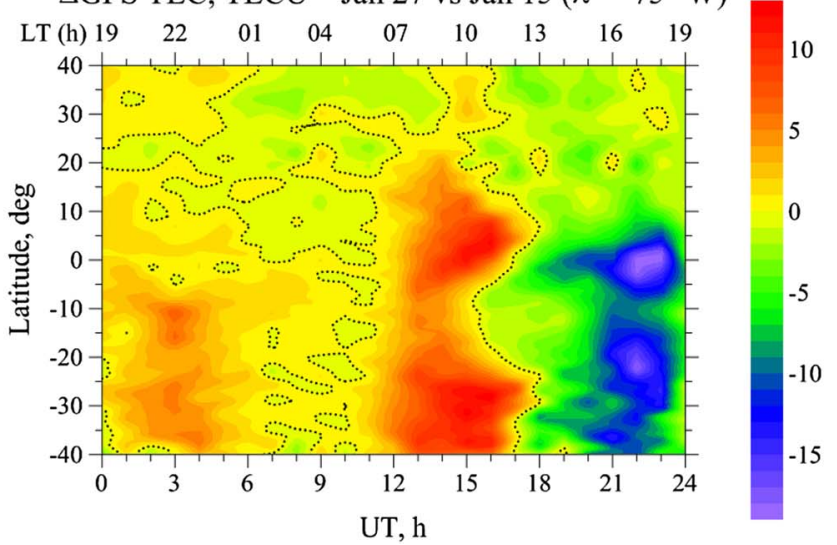

Fig. 3. Diurnal variation of the TEC latitudinal profile on 15 January 2009 (top panel), and TEC disturbances on 27 (bottom panel) January 2009: (left) EAGLE model results vs. (right) GPS TEC measurements.

starting on 18 January that could be associated with the SSW event. A significant drop in the tropical lower thermospheric temperature on 22 January and a strong warming on 27 January can be seen in Figure 2. On the same days, the corresponding changes in the Pedersen conductivity occur near to the equator with a small displacement towards the Southern Hemisphere: (1) a local minimum in the Pedersen conductivity can be seen on 22 January; (2) there is an occurrence of the main maximum in the Pedersen conductivity on 27 January. Hall conductivity does not show any major changes that could be associated with tropical temperature disturbances during the SSW event. During the SSW the horizontal winds change direction. In this case, the link between changes in the meridional wind and the zonal electric field during the SSW period is most clearly seen. Thus, in this subsection we conclude that: (1) the SSW affects ionospheric conductivities; (2) the cooling of the lower tropical thermosphere has an impact on the zonal electric field close to the equator, leading to the SSW-related vertical plasma drift.

\subsection{Upper atmosphere anomalies in the American longitudinal sector on 27 January 2009}

Another important aspect is the identification of physical mechanisms explaining the low-latitude TEC anomalous variability connected to lower atmospheric processes. After the first model attempts to reproduce the strong ionospheric SSW signature (Goncharenko et al., 2010b), many numerical experiments with varying degrees of success in reproducing low-latitude TEC disturbances in the American longitudinal sector were presented (Jin et al., 2012; Klimenko et al., 2015; Pedatella et al., 2016, 2018). Klimenko et al. (2015) demonstrated that only the inclusion of additional upward and downward electromagnetic plasma drift velocities to the GSM TIP model allowed the observed pre-noon positive and daytime negative TEC disturbances in the equatorial ionization anomaly region associated with the 2009 SSW event to be reproduced. A multi-model comparison of the ionospheric variability during the 2009 SSW revealed that, although numerous numbers of features of the ionosphere variability are captured by the simulations, there are significant differences between simulations and observations (Pedatella et al., 2016). Figure 3 compares the simulated and observed diurnal cycle of TEC before and after the SSW, on the 15 and 27 January 2009 over the American longitudinal sector $\left(75^{\circ} \mathrm{W}\right)$. The simulated magnitude of the TEC diurnal/semidiurnal variations is much weaker than the observed TEC magnitude. However, a good qualitative agreement between simulation results and observational data is visible for both the TEC diurnal variation on 15 January and TEC anomalies associated with the January 2009 SSW event. 
We choose 15 January as the reference day because TEC on this day was typical for pre-SSW conditions. Using 16 January or monthly mean values as a reference does not lead to any morphological changes in SSW-related TEC disturbances. For 27 January 2009, the EAGLE model reproduces well the temporal variability of the observed latitudinal structure of ionospheric disturbances in TEC, such as the enhancement of the Equatorial Ionization Anomaly (EIA) in pre-noon hours, as well as the equatorial and low-latitude TEC decrease in the afternoon. The model underestimates the magnitude of the pre-noon positive TEC disturbances, which does not exceed 4-5 TECU. The observed daytime TEC decrease is well matched with the EAGLE results. From this, we can conclude that the EAGLEsimulated ionospheric variability tends to be in better agreement with the observations in the afternoon compared to the pre-noon local time. The same conclusion was reached by Pedatella et al. (2016) based on a multimodel-data comparison. In addition to the pre-noon TEC enhancement and afternoon TEC reduction, the EAGLE model reproduces well another, undocumented, feature of the observed TEC response to the 2009 SSW event: (1) an evening time EIA enhancement in TEC; (2) nighttime negative disturbances in TEC. The second finding confirms the recently proposed relationship between the SSW event and nighttime decrease in TEC (Goncharenko et al., 2018) for another SSW event in 2013. So, given that the EAGLE model results adequately reproduce most of the observed features in TEC diurnal variations, we can use them to investigate the formation mechanism of such TEC disturbances.

For interpretation of the low-latitude TEC response to the 2009 SSW event, we considered disturbances of the zonal and meridional components of the electric field. Zonal electric fields in the equatorial region are responsible for the vertical plasma drift. Meridional electric fields produce mainly a zonal plasma drift that can lead to significant disturbances close to the terminator. Our comparative analysis of both components of electric field disturbances (Fig. 4) and TEC disturbances (Fig. 3) reveals that: (1) the pre-noon EIA enhancement in TEC is associated with an additional eastward electric field (upward plasma drift); (2) the westward electric field is a primary formation mechanism of the afternoon EIA reduction; (3) zonal electric field (vertical plasma drift) disturbances cannot explain an additional post-sunset EIA enhancement in TEC. At local evening, the additional zonal electric field is westward, producing a downward plasma drift in the region with a higher level of recombination processes that, therefore, should lead to a TEC reduction in the EIA region. In this case, disturbances of the meridional electric field that produce an eastward plasma drift (plasma with greater density transport from earlier hours to later ones) are the primary source of the observed post-sunset positive TEC disturbances in the EIA region. The eastward plasma drift also contributes to the pre-sunrise (nighttime) negative disturbances in TEC with a maximum reduction at 10-12 UT. During this local time segment, zonal electric field disturbances lead to: (1) an additional TEC reduction at 10-11 UT due to downward plasma transport; (2) a vertical upward plasma drift at 11-12 UT counteracting the TEC reduction produced by an additional eastward plasma drift due to an additional meridional electric field. Therefore, our analysis reveals an important role of the meridional electric field in the formation of the low-latitude TEC response to the SSW event.
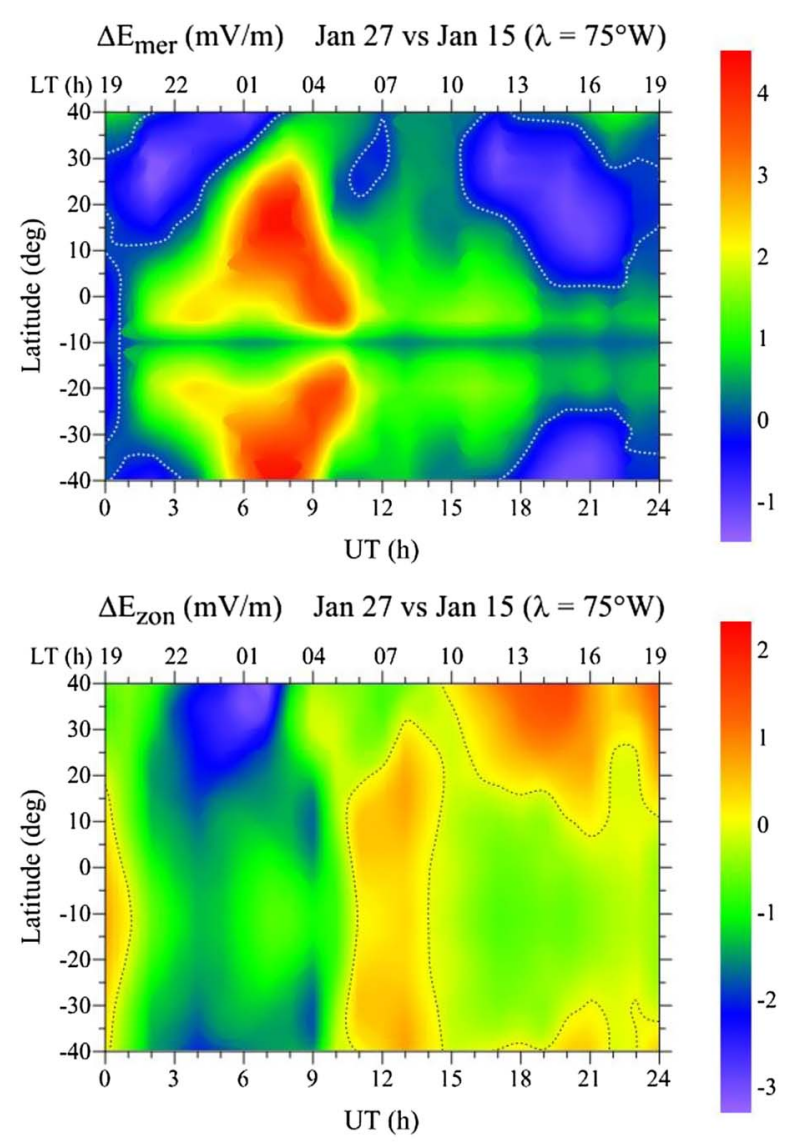

$\Delta$ Ezonal $(\mathrm{mV} / \mathrm{m}) \quad$ SSW vs Quiet $\left(\lambda=75^{\circ} \mathrm{W}\right)$

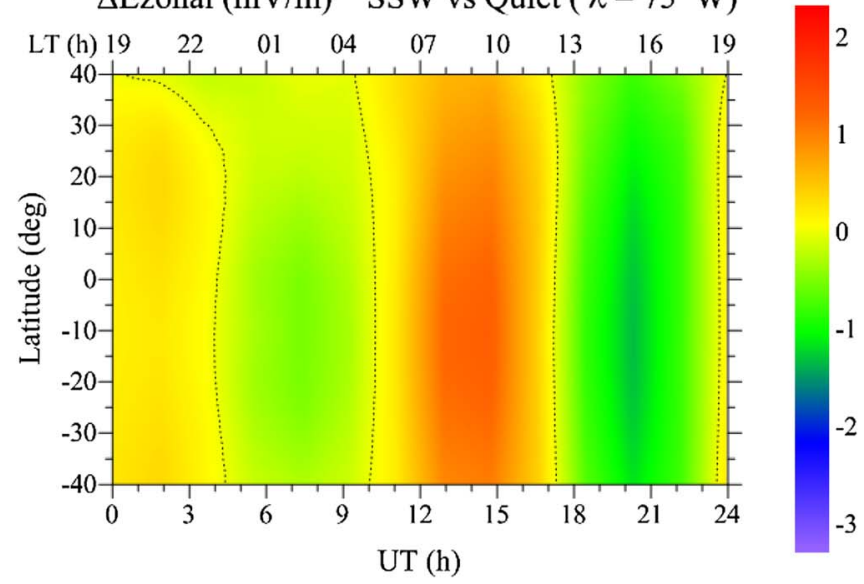

Fig. 4. EAGLE-simulated diurnal variations of the meridional (top panel) and zonal (middle panel) electric field disturbances on 27 January 2009 at $40^{\circ} \mathrm{S}-40^{\circ} \mathrm{N}$ latitudes in the American longitudinal sector $\left(75^{\circ} \mathrm{W}\right)$ and $175 \mathrm{~km}$ altitude. The bottom panel presents the zonal electric field disturbances that were obtained with the standalone GSM TIP model using the TIME-GCM model output with an additional electric potential that allowed for the reproduction of TEC disturbances during the 2009 SSW event (Klimenko et al., 2015).

This conclusion will likely have implications for the further analysis of the formation of nighttime ionospheric holes, recently discussed by Goncharenko et al. (2018). 
$\Delta \mathrm{V}_{\text {zon }}(\mathrm{m} / \mathrm{s}) \quad \mathrm{h}=120 \mathrm{~km} \quad$ Jan 27 vs Jan $15\left(\lambda=75^{\circ} \mathrm{W}\right)$

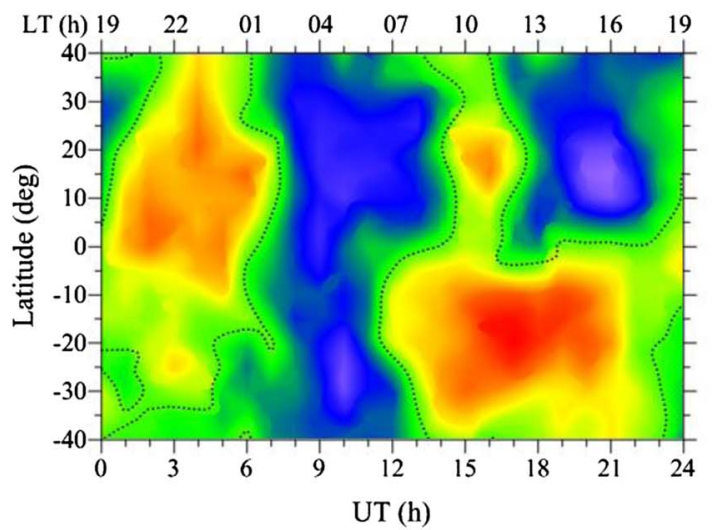

$\Delta \sigma_{\mathrm{P}}\left(10^{-3} \mathrm{~S} / \mathrm{m}\right) \quad \mathrm{h}=120 \mathrm{~km} \quad \operatorname{Jan} 27$ vs Jan $15\left(\lambda=75^{\circ} \mathrm{W}\right)$

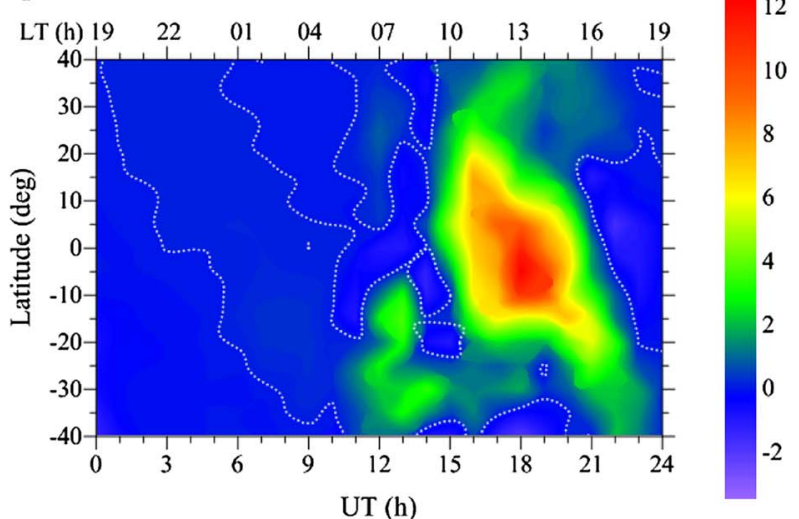

$\Delta \mathrm{V}_{\text {mer }}(\mathrm{m} / \mathrm{s}) \quad \mathrm{h}=120 \mathrm{~km} \quad J a n 27$ vs Jan $15\left(\lambda=75^{\circ} \mathrm{W}\right)$

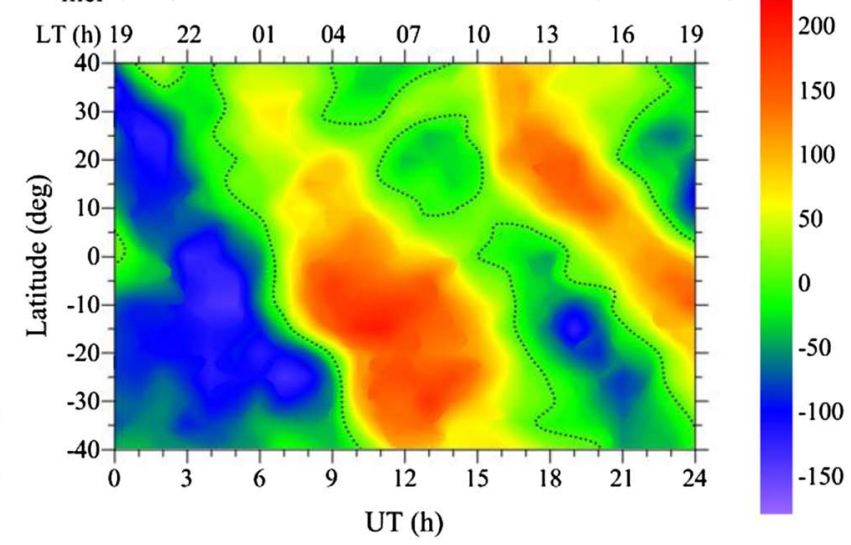

$\Delta \sigma_{\mathrm{H}}\left(10^{-3} \mathrm{~S} / \mathrm{m}\right) \quad \mathrm{h}=120 \mathrm{~km} \quad$ Jan 27 vs Jan $15\left(\lambda=75^{\circ} \mathrm{W}\right)$

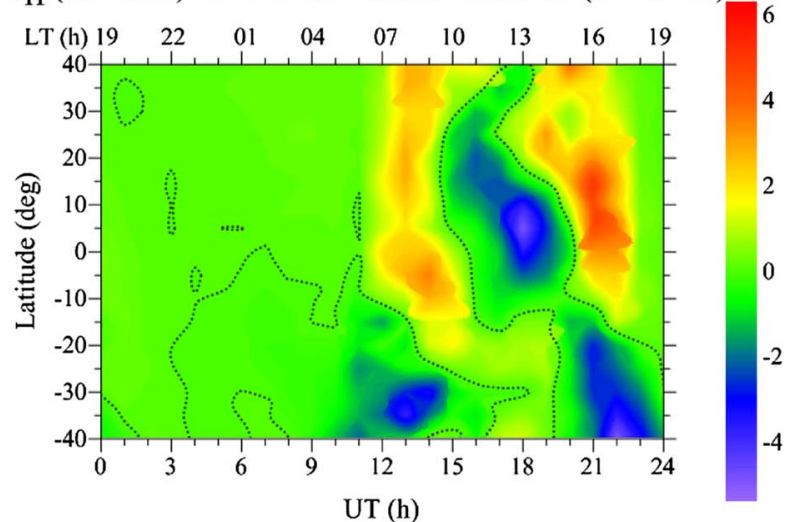

Fig. 5. EAGLE-simulated diurnal variations of the disturbances in zonal and meridional thermospheric wind (top panels) and Pedersen and Hall conductivities (bottom panels) on 27 January 2009 at the latitude range from $40^{\circ} \mathrm{S}$ to $40^{\circ} \mathrm{N}$ in the American longitudinal sector $\left(75^{\circ} \mathrm{W}\right.$ ) and $120 \mathrm{~km}$ altitude.

Figure 4 also presents a comparison of the zonal electric field disturbances in the American longitudinal sector from the GSM TIP model, used by Klimenko et al. (2015) for the successful reproduction of TEC disturbances during the 2009 SSW event, with the EAGLE results for 27 January 2009. Note that GSM TIP model results presented in (Klimenko et al., 2015) are successfully reproduced 2009 SSW response in vertical ion plasma drift over Jicamarca. From Figure 4 the similarity between EAGLE and previous GSM TIP model results is evident. There are some differences, for example the lower additional pre-noon eastward and afternoon westward electric field in the EAGLE results potentially could be responsible for some quantitative disagreement (underestimation) with the observed TEC disturbances. Despite this disagreement, by using the EAGLE model results we can try now to answer one of the main questions in the interpretation of ionospheric SSW responses: what is the generation mechanism of the zonal electric field disturbances during the 2009 SSW event?

To answer this question, we analyzed the perturbations of the thermospheric winds, as well as the Hall and Pedersen conductivities at $120 \mathrm{~km}$ altitude in the American longitudinal sector (Fig. 5). One hundred and twenty kilometers is chosen since it is the altitude with the most effective formation of a dynamic electric field in the ionosphere. The perturbations of the zonal and meridional wind are significant, reaching
$200 \mathrm{~m} / \mathrm{s}$ and with a pronounced semi-diurnal variability. Both conductivities also experience significant changes during the SSW. In this case, the greatest perturbations and, accordingly, temporal variations of the conductivities are observed over 10-24 UT, that is, at the illuminated time of day. These significant changes in wind speed and conductivities lead to the appearance of significant spatial gradients in these parameters, which form the spatial gradient of the electric potential, and therefore disturbances in both components of the electric field. It is important to note here that, along with the wind disturbances that are the main source for the formation of an electric field dynamo in the ionosphere, the interpretation of ionospheric responses to SSWs should consider some contribution to the electric field disturbances from the conductivity perturbations.

According to previous investigations and the EAGLE model results, the primary mechanism for the formation of pre-noon positive and afternoon negative TEC disturbances at low latitudes during the 2009 SSW event is the perturbation of the zonal electric field (the vertical $E \times B$ plasma drift) (Goncharenko et al., 2010a, 2010b; Jin et al., 2012; Klimenko et al., 2015; Pedatella et al., 2016). Therefore, initially we try to explain all TEC changes during the SSW as a result of zonal and meridional electric fields. As additional information, we present EAGLE model results of all other mechanisms $\left(\mathrm{O} / \mathrm{N}_{2}\right.$ and meridional neutral wind at $300 \mathrm{~km}$ height) that can be 
$\mathrm{n}(\mathrm{O}) / \mathrm{n}(\mathrm{N} 2) \quad \mathrm{h}=300 \mathrm{~km} \quad \operatorname{Jan} 15\left(\lambda=75^{\circ} \mathrm{W}\right)$

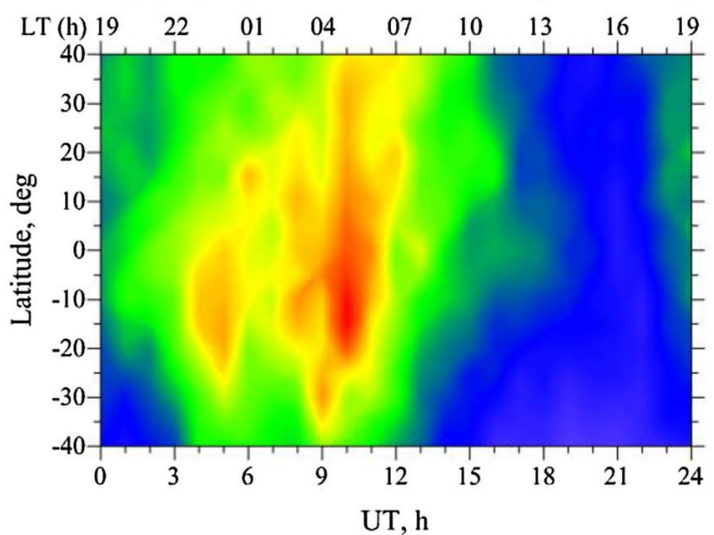

$\Delta \mathrm{n}(\mathrm{O}) / \mathrm{n}(\mathrm{N} 2) \quad \mathrm{h}=300 \mathrm{~km} \quad \operatorname{Jan} 27$ vs Jan $15\left(\lambda=75^{\circ} \mathrm{W}\right)$

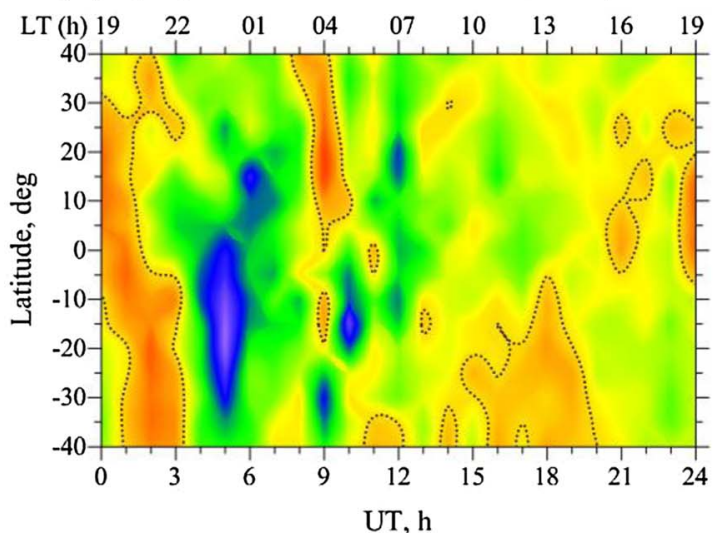

$\operatorname{Vn} \operatorname{mer}(\mathrm{m} / \mathrm{s}) \mathrm{h}=300 \mathrm{~km} \quad \operatorname{Jan} 15\left(\lambda=75^{\circ} \mathrm{W}\right)$
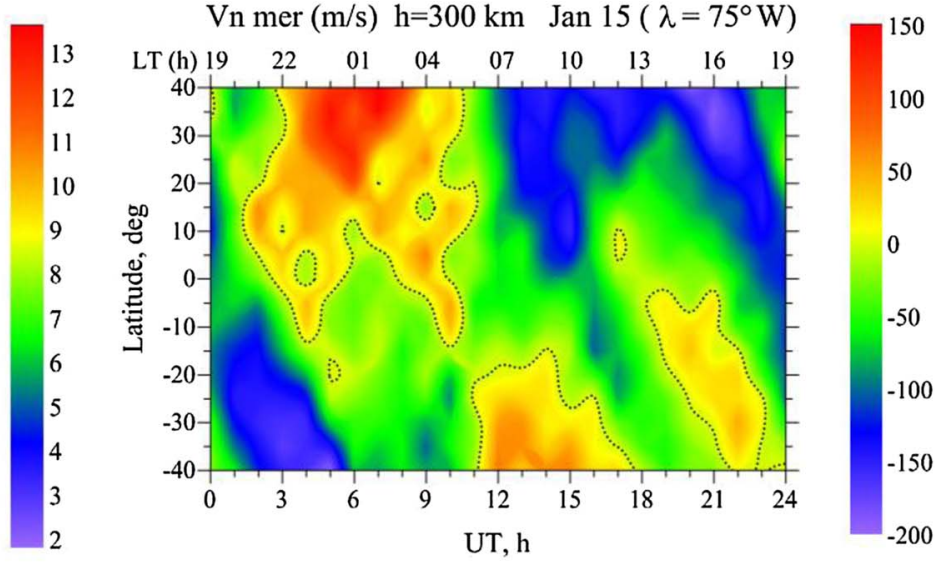

$\Delta \operatorname{Vn~mer~}(\mathrm{m} / \mathrm{s}) \quad \mathrm{h}=300 \mathrm{~km} \quad \operatorname{Jan} 27$ vs Jan $15\left(\lambda=75^{\circ} \mathrm{W}\right)$

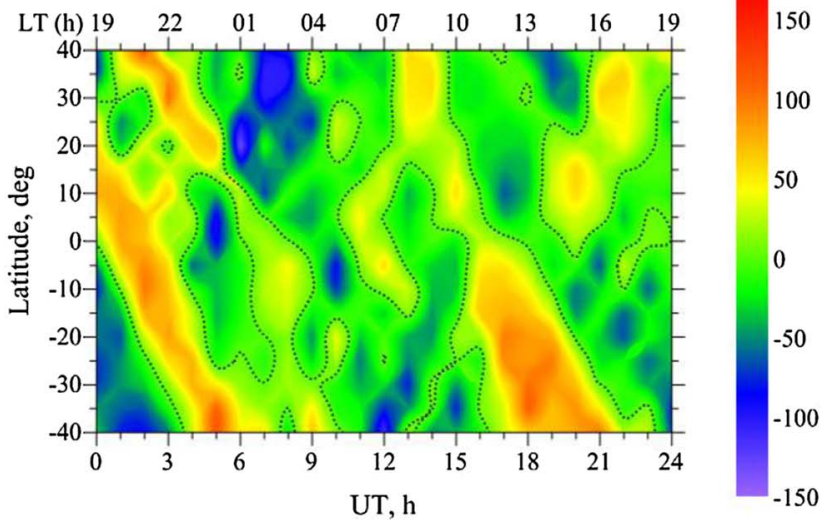

Fig. 6. EAGLE-simulated diurnal variation of the latitudinal profile of $\mathrm{O} / \mathrm{N}_{2}$ ratios (left) and meridional thermospheric winds (right) on 15 January 2009 (top panel) and their disturbances on 27 January 2009 (bottom panel) at the latitude range from $40^{\circ} \mathrm{S}$ to $40^{\circ} \mathrm{N}$ in the American longitudinal sector $\left(75^{\circ} \mathrm{W}\right)$ and $300 \mathrm{~km}$ altitude.
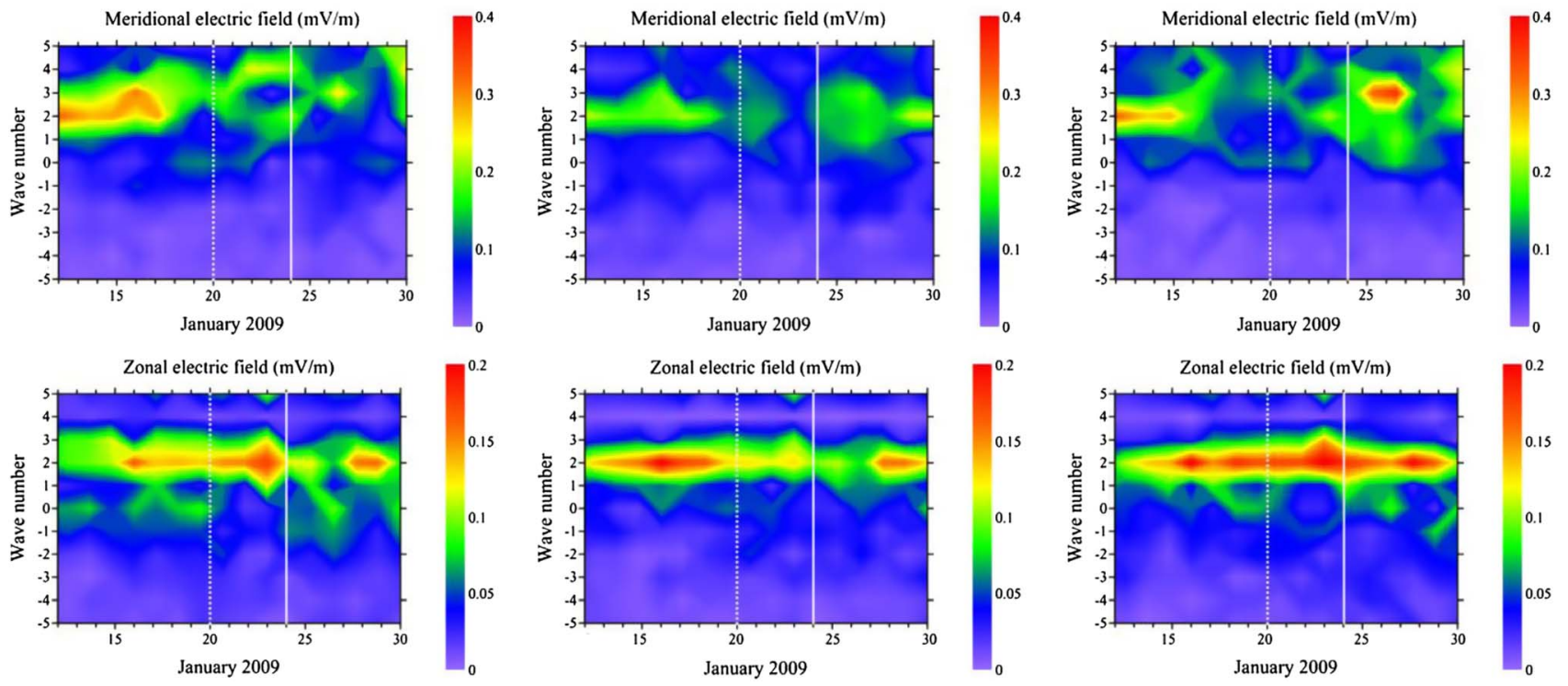

Fig. 7. Spectra of the EAGLE-simulated semidiurnal tidal variations in the meridional (top) and zonal (bottom) components of electric field at $20^{\circ} \mathrm{N}$ (left), equator (middle), and $20^{\circ} \mathrm{S}$ (right) at $175 \mathrm{~km}$ altitude. Vertical lines indicate the onset (dotted) and peak (solid) of the $2009 \mathrm{SSW}$. 

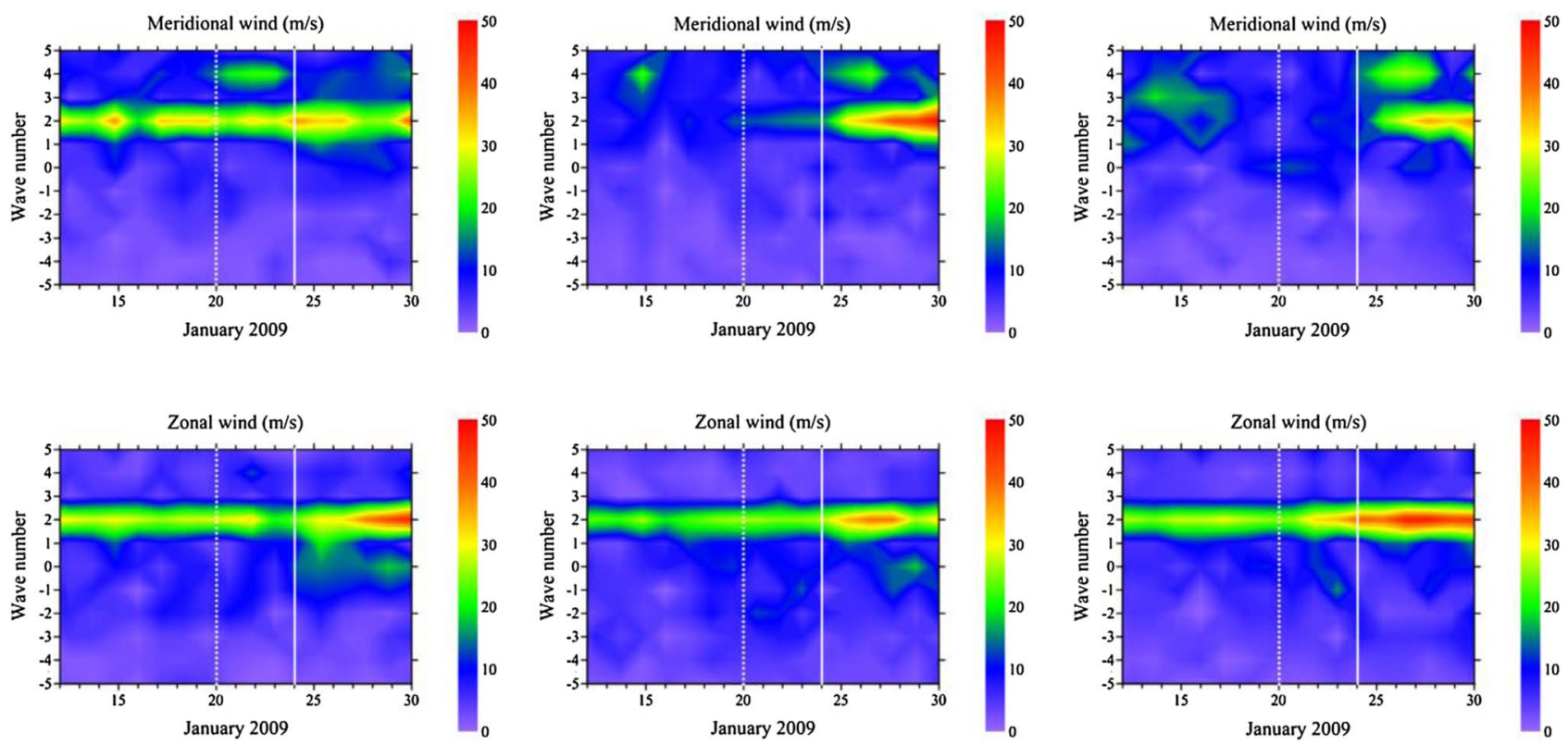

Fig. 8. Spectra of the EAGLE-simulated semidiurnal tidal variations in the meridional (top) and zonal (bottom) components of wind at $20^{\circ} \mathrm{N}$ (left), equator (middle), and $20^{\circ} \mathrm{S}$ (right) at $114 \mathrm{~km}$ altitude. Vertical lines indicate the onset (dotted) and peak (solid) of the $2009 \mathrm{SSW}$.

responsible for the observed TEC changes (Fig. 6). According to the presented wind and $\mathrm{O} / \mathrm{N}_{2}$ disturbances, these parameters cannot be neglected in an explanation of the SSW-related TEC disturbances at low-latitudes. The key mechanism for the prenoon positive TEC disturbances is an upward vertical plasma drift due to an eastward electric field. On the time interval 12:00-15:00 UT, the SSW-related disturbances in $\mathrm{O} / \mathrm{N}_{2}$ slightly reduce the positive TEC disturbances, which are slightly enhanced by an additional eqatorward wind that is formed at this time. From 15:00 till 24:00 UT, the $\mathrm{O} / \mathrm{N}_{2}$ disturbances provide a clue to explain the northern-southern asymmetry of the modeled positive and afternoon negative low-latitude TEC disturbances. In both cases, the distribution of $\mathrm{O} / \mathrm{N}_{2}$ disturbances leads to an increase in TEC disturbances in the Southern hemisphere, and a decrease in the Northern hemisphere.

\subsection{Analysis of tidal variations in the lower thermosphere and the electric field}

To understand an impact of tidal waves on the formation of a low-latitude anomalous electric field during an SSW period, we analyze the spectral structure of tidal variations in several simulated parameters. The tidal wave exploration is based on the methods of harmonic analysis and is described in detail by Karpov et al. (2018). As concluded from Figures 4 and 5, the perturbations of the horizontal wind at lower thermosphere and ionospheric electric fields during the SSW are significant and possess a pronounced semi-diurnal variability. The spectral analysis of the EAGLE results (see Figs. 7 and 8) showed that, for the near-equatorial region, the semidiurnal variations of horizontal thermospheric winds and electric fields are attributed mainly to migrating solar tides (SW2). We found (see Figs. 7 and 9) a decrease in the amplitudes of the semidiurnal variations in the meridional and zonal components of the electric field during the SSW (17-23 January), and a tendency of its further

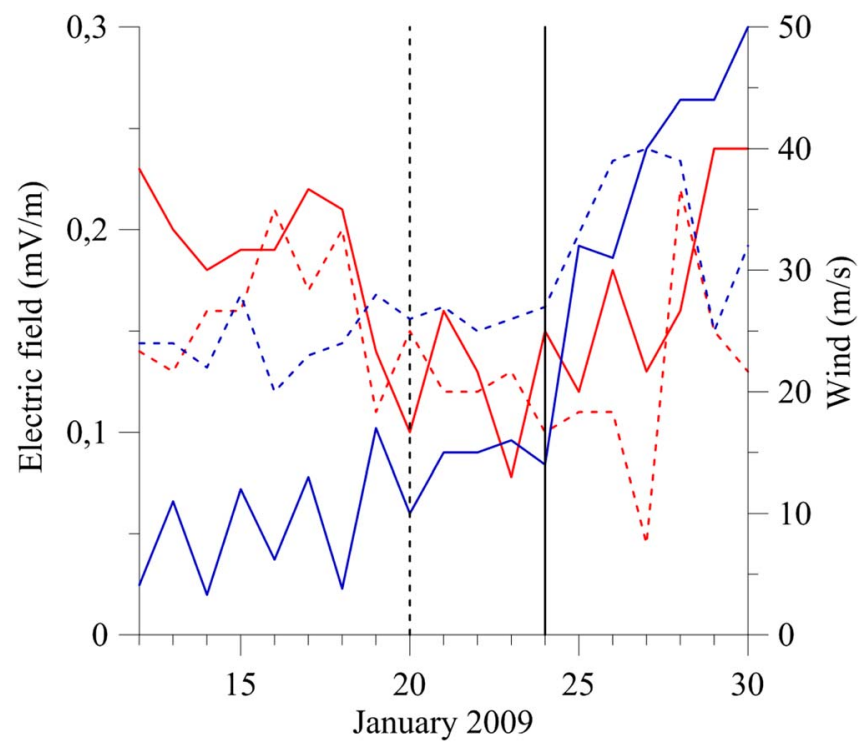

Fig. 9. EAGLE-simulated semidiurnal solar migrating (SW2) tidal variations in the meridional (solid lines) and zonal (dashed lines) wind components (blue lines) and the electric field (red lines) at equator. Vertical lines indicate the onset (dotted) and peak (solid) of the 2009 SSW.

increase (decrease) in meridional (zonal) electric fields after the SSW maximum (23 January). The amplitude of the migrating semidiurnal solar tide in the horizontal wind also increases after the SSW-related maximum temperature anomaly in the stratosphere (see Figs. 8 and 9). A similar behavior of semidiurnal tides in the lower thermosphere, i.e. an increase in the amplitudes of tides in the equatorial region after the SSW, was revealed by Jin et al. (2012) using both simulations and 

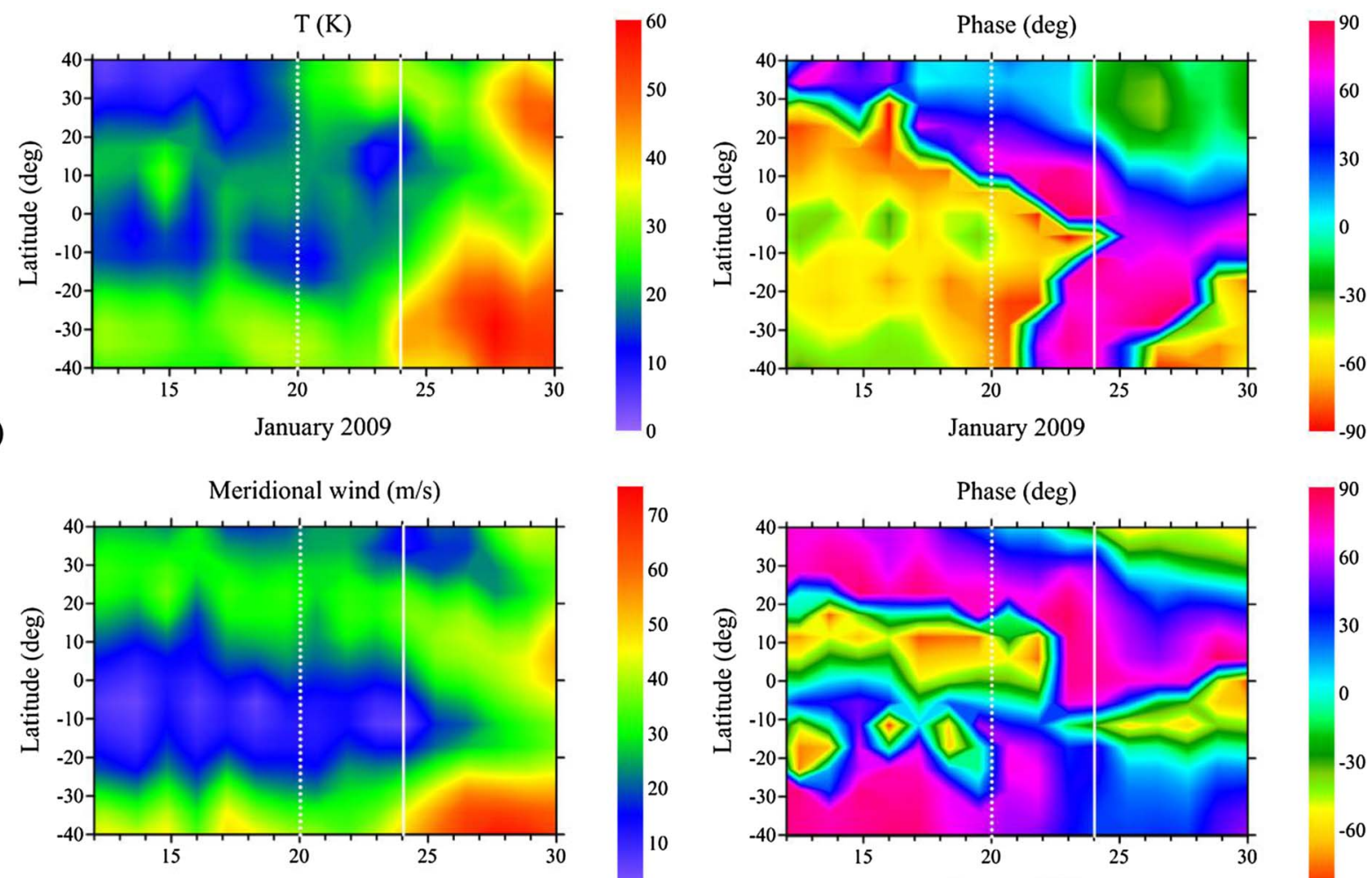

b)

January 2009
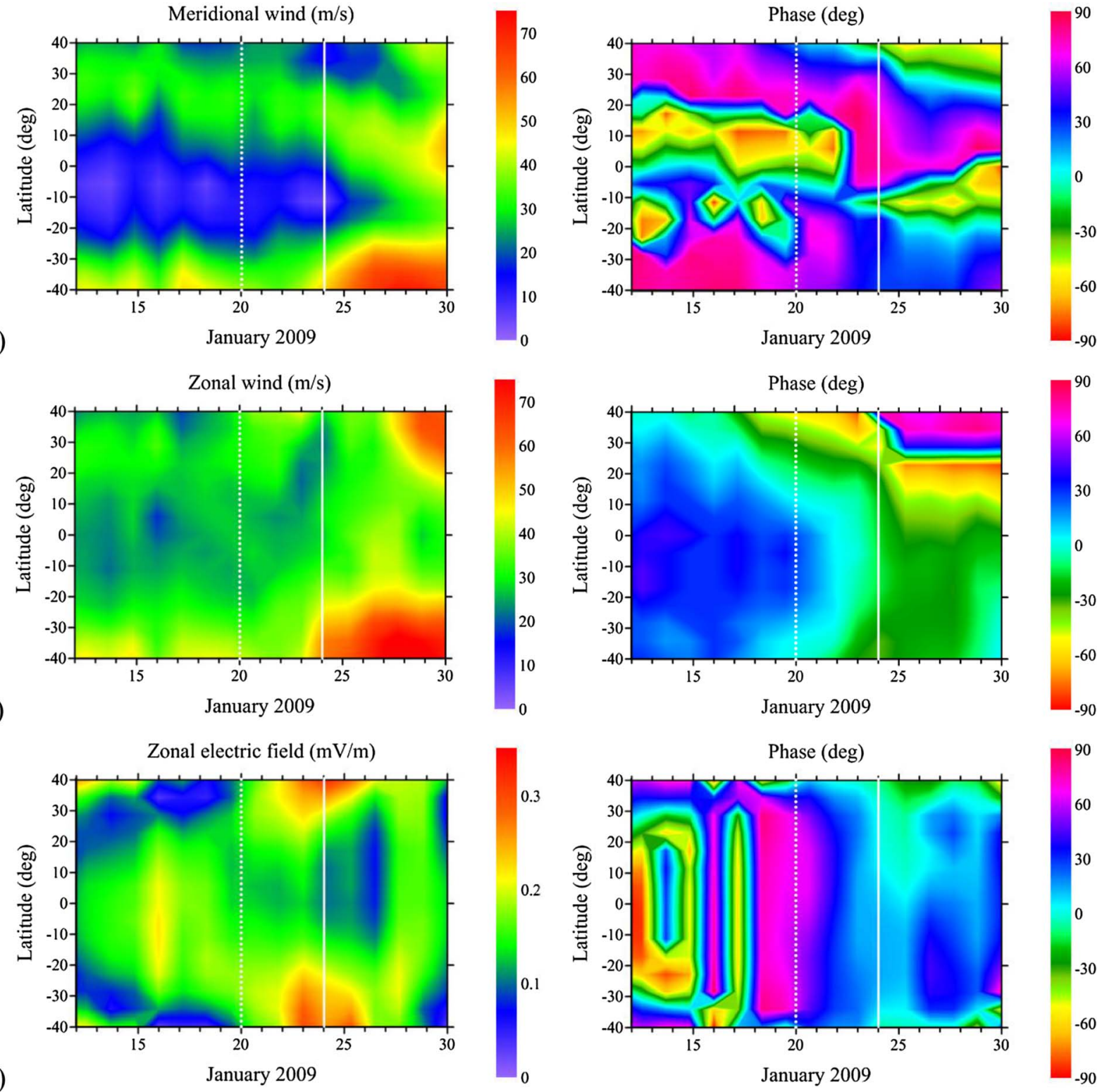

Fig. 10. Magnitudes (left panels) and phases (right panels) of the semidiurnal migrating solar tide in the (a) neutral temperature, (b) meridional wind, and (c) zonal wind at $114 \mathrm{~km}$ altitude as well as (d) the zonal electric field simulated with EAGLE. Vertical lines indicate the onset (dotted) and peak (solid) of the 2009 SSW. 
observations. Figures 7 and 8 show that periods of the spectral change of tidal wind variations in the lower thermosphere coincide with the periods of change in the spectral characteristics of variations in the components of the electric field. We can assume that the spectral structure of the semidiurnal variations of components of the electric field and its dramatic change during the SSW period is a consequence of disturbances due to nonlinear interactions of factors that drive the dynamo electric field.

Comparison of the diurnal, semidiurnal, and terdiurnal tide properties in the thermosphere, and in the zonal electric field, show that the semidiurnal migrating solar tides (SW2) experience the greatest and the most evident changes during the SSW event. Figure 10 shows the amplitudes and phases of SW2 in the temperature and zonal wind of the lower thermosphere (at $114 \mathrm{~km}$ altitude) and in the zonal component of the electric field. As can be seen from Figure 10, the amplitudes of SW2 in thermospheric parameters increase during the SSW (on 22 January), reaching their maximum values on 26-27 January over middle latitudes. After that, the region with the elevated amplitudes of SW2 in the neutral temperatures and zonal winds shift to the equator. Previous theoretical studies and observations (Wang et al., 2011; Fuller-Rowell et al., 2011a; Jin et al., 2012; Pedatella et al., 2018) revealed a similar evolution of SW2 during the SSW in January 2009. On the other hand, SW2 phase anomalies appear over the middle latitudes much earlier (on 15 January) and move equatorward in the following days. Comparative analyses of our simulations show that the obtained changes in the amplitudes and phases of SW2 in thermospheric parameters significantly affect the zonal electric field. In the equatorial region, the decrease of the zonal electric field amplitude is observed between the 15 and 27 of January and coincides with the decrease of the wave amplitude in equatorial temperature. At middle latitudes, the maximum increase in the electric field SW2 amplitude occurs over 22-27 January and coincides with the increase in the amplitudes of SW2 in thermospheric parameters. The phase of the zonal component of the electric field is rather stable until 22 January, but dramatically (up to $\sim 90^{\circ}$ ) changes during the following 4-5 days.

Consistent variations of the amplitudes and phases of SW2 in the lower thermospheric temperature, wind, and the zonal electric field during the SSW event suggest that the formation of the anomalous zonal electric field in the equatorial region is directly linked to perturbations of the SW2 amplitude and phase during the SSW. Earlier, Jin et al. (2012) and Pedatella \& Liu (2013) reported that tidal variability in the lower thermosphere can generate perturbations of diurnal and semi-diurnal variations of the ionospheric plasma parameters and the electric field during SSW periods. As a possible source of these disturbances, these studies considered a change in the background state of the atmosphere that affects the vertical propagation of tidal waves and the spatial distribution of ozone. Our results support their conclusions and provide a more detailed description on how the tidal waves in the lower thermosphere influence the structure of the electric field. Our results show that the phase change of the semidiurnal migrating solar tide in the thermospheric parameters, at altitudes where the dynamo electric field is generated, leads to a consistent SW2 phase change in the zonal electric field. These phase changes, together with the previously revealed SW2 amplitude alteration, result in a formation of anomalous diurnal variations of the electromagnetic plasma drift at the equator that ultimately leads to the TEC disturbances in the EIA region that occurred during the 2009 SSW event.

\section{Conclusions}

This study presents first results obtained using the new EAGLE model that combines the HAMMONIA and GSM TIP models. Our modeling results reproduce the following previously observed and explained phenomena during the 2009 SSW event: (1) mesospheric cooling, lower thermospheric warming, and thermospheric cooling over high latitudes of the Northern Hemisphere; (2) stratospheric cooling and mesospheric warming over the tropics; (3) pre-noon EIA enhancement formed by the eastward electric field intensification (upward vertical plasma drift); (4) afternoon EIA weakening and TEC decrease at low-latitudes explained by westward electric field intensification (downward vertical plasma drift). The presented results thus confirm that the vertical plasma drift (zonal electric field) plays a major role in the daytime low-latitude TEC variability during the 2009 SSW event.

Using both model and observations, we demonstrate an occurrence of a thermospheric cooling at low latitudes during the 2009 SSW event. For the first time we reveal that maximal SSW-related cooling is occurring in the lower thermosphere, which (as shown in our investigation) is important for the generation of the ionospheric dynamo electric field disturbances at ionospheric E-region heights $(100-120 \mathrm{~km})$. Our simulated equatorial zonal electric field disturbance agrees reasonably well with observations of ion drift velocity at the Jicamarca location. We demonstrate that temperature perturbations in the lower thermosphere during the SSW substantially affect thermospheric winds, which is an important factor for the formation of the dynamo electric field disturbances. It is worth to note that along with the wind disturbance, which is the main source of the formation of an electric field dynamo in the ionosphere, perturbations of the ionospheric conductivity also make a significant contribution to the formation of the electric field response to SSW.

We highlighted the observed and modeled low-latitude TEC enhancement at post-sunset hours and TEC reduction at presunrise hours on 27 January 2009 that can be explained by an appearance of additional eastward plasma drift (plasma transport from earlier to later hours). For the first time, we reveal a very important role of meridional electric field disturbances in the formation of the low-latitude TEC response to the 2009 SSW event at post-sunset and pre-sunrise hours in the American longitudinal sector.

Tidal variations simulated with the EAGLE model are consistent with a previously observed and simulated intensification of the semidiurnal migrating solar tide (SW2) in the lower thermosphere. Here, we show that the change of the SW2 phase in neutral winds at altitudes of the dynamo electric field generation leads to a change of the SW2 phase in the zonal electric field during the January 2009 SSW. Changes in the phase and amplitude of the semidiurnal variations of the zonal electric field lead to the occurrence of anomalous diurnal variations in the vertical velocity of the electromagnetic plasma drift at the 
equator observed during the 2009 SSW. These $E \times B$ drift changes are the main cause of the observed TEC disturbances in the equatorial ionization anomaly region during the 2009 SSW event.

Acknowledgements. Authors thank Hauke Schmidt and Katharina Meraner for their help with model development and William Ball for his help in improvement of the manuscript. Authors thank Dr. Norbert Jakowski for his editorial work in the review process. This investigation was performed with the financial support of the Russian Science Foundation Grant No. 17-17-01060. B. Funke acknowledges support by the Spanish MCINN (ESP2017-87143-R) and EC FEDER funds. The EAGLE model results are available upon request to the authors. We acknowledge use of GNSS data provided by UNAVCO (ftp://data-out.unavco.org), IGS (ftp://cddis. gsfc.nasa.gov), RBMC (ftp://geoftp.ibge.gov.br/RBMC/), RAMSAC (www.igm. gov.ar/NuestrasActividades/Geodesia/ Ramsac/). The editor thanks two anonymous referees for their assistance in evaluating this paper.

\section{References}

Bermejo-Pantaleón D, Funke B, López-Puertas M, García-Comas M, Stiller GP, et al. 2011. Global observations of thermospheric temperature and nitric oxide from MIPAS spectra at $5.3 \mu \mathrm{m}$. J Geophys Res 116: A10313. DOI: 10.1029/2011JA016752.

Bessarab FS, Korenkov YuN, Klimenko MV, Klimenko VV, Karpov IV, Ratovsky KG, Chernigovskaya MA. 2012. Modeling the effect of sudden stratospheric warming within the thermosphere-ionosphere system. J Atmos Sol-Terr Phys 90-91: 77-85. DOI: 10.1016/j.jastp.2012.09.005.

Butler AH. 2015. Defining sudden stratospheric warmings. Bull Am Meteorol Soc 96(11): 1913-1928. DOI: 10.1175/BAMS-D-1300173.1

Chau JL, Goncharenko LP, Fejer BG, Liu HL. 2012. Equatorial and low latitude ionospheric effects during sudden stratospheric warming events. Space Sci Rev 168: 385-417. DOI: 10.1007/ s11214-011-9797-5.

Fejer BG, Tracy BD, Olson ME, Chau JL. 2011. Enhanced lunar semidiurnal equatorial vertical plasma drifts during sudden stratospheric warmings. Geophys Res Lett 38: L21104. DOI: 10.1029/2011GL049788.

Fischer H, Birk M, Blom C, Carli B, Carlotti M, et al. 2008. MIPAS: An instrument for atmospheric and climate research. Atmos Chem Phys 8: 2151-2188. DOI: 10.5194/acp-8-2151-2008.

Forbes JM, Palo SE, Zhang X. 2000. Variability of the ionosphere. J Atmos Sol-Terr Phys 62: 685-693. DOI: 10.1016/S1364-6826 (00)00029-8.

Forbes JM, Zhang X. 2012. Lunar tide amplification during the January 2009 stratosphere warming event: Observations and theory. J Geophys Res 117: A12312. DOI: 10.1029/2012JA017963.

Fuller-Rowell T, Wang H, Akmaev R, Wu F, Fang T-W, Iredell M, Richmond A. 2011a. Forecasting the dynamic and electrodynamic response to the January 2009 sudden stratospheric warming. Geophys Res Lett 38: L13102. DOI: 10.1029/2011GL047732.

Fuller-Rowell T, Akmaev R, Wu F, Fedrizzi M, Viereck RA, Wang H. 2011b. Did the January 2009 sudden stratospheric warming cool or warm the thermosphere? Geophys Res Lett 38: L18104. DOI: $10.1029 / 2011$ GL048985.
Funke B, Lypez-Puertas M, Bermejo-Pantaleyn D, Garcha-Comas M, Stiller GP, von Clarmann T, Kiefer M, Linden A. 2010. Evidence for dynamical coupling from the lower atmosphere to the thermosphere during a major stratospheric warming. Geophys Res Lett 37: L13803. DOI: 10.1029/2010GL043619.

Funke B, Ball W, Bender S, Gardini A, Harvey VL, et al. 2017. HEPPA-II model-measurement intercomparison project: EPP indirect effects during the dynamically perturbed $\mathrm{NH}$ winter 2008-2009. Atmos Chem Phys 17: 3573-3604. DOI: 10.5194/acp17-3573-2017.

Goncharenko LP, Coster AJ, Chau JL, Valladares CE. 2010a. Impact of sudden stratospheric warmings on equatorial ionization anomaly. J Geophys Res 115: A00G07. DOI: 10.1029/2010JA015400.

Goncharenko LP, Chau JL, Liu H-L, Coster AJ. 2010b. Unexpected connections between the stratosphere and ionosphere. Geophys Res Lett 37: L10101. DOI: 10.1029/2010GL043125.

Goncharenko LP, Coster AJ, Zhang S-R, Erickson PJ, Benkevitch L, et al. 2018. Deep ionospheric hole created by sudden stratospheric warming in the nighttime ionosphere. J Geophys Res 123: 76217633. DOI: $10.1029 / 2018 J A 025541$.

Jin H, Miyoshi Y, Pancheva D, Mukhtarov P, Fujiwara H, Shinagawa H. 2012. Response of migrating tides to the stratospheric sudden warming in 2009 and their effects on the ionosphere studied by a whole atmosphere-ionosphere model GAIA with COSMIC and TIMED/SABER observations. J Geophys Res 117: A10323. DOI: 10.1029/2012JA017650.

Karpov IV, Bessarab FS, Borchevkina OP, Artemenko KA, Klopova AI. 2018. Modeling of the of mesospheric IGV influence on planetary and tidal waves in the thermosphere and ionosphere during the sudden stratospheric warming of 2009. Geomagn Aeron 58(4): 526-539. DOI: 10.1134/S0016793218040084

Klimenko MV, Klimenko VV, Bryukhanov VV. 2007. Numerical modeling of the equatorial electrojet UT-variation on the basis of the model GSM TIP. Adv Radio Sci 5: 385-392. DOI: 10.5194/ ars-5-385-2007.

Klimenko MV, Klimenko VV, Bessarab FS, Korenkov YN, Liu H, Goncharenko LP, Tolstikov MV. 2015. Study of the thermospheric and ionospheric response to the 2009 sudden stratospheric warming using TIME-GCM and GSM TIP models first results. J Geophys Res 120: 7873-7888. DOI: 10.1002/ 2014JA020861.

Klimenko MV, Bessarab FS, Sukhodolov TV, Klimenko VV, Korenkov YN, et al. 2018. Ionospheric effects of the sudden stratospheric warming in 2009: Results of simulation with the first version of the EAGLE model. Russ J Phys Chem B 12(4): 760-770. DOI: $10.1134 /$ S1990793118040103.

Klimenko VV, Klimenko MV, Bessarab FS, Sukhodolov TV, Rozanov EV. 2019. The dependence of four-peak longitudinal structure of the tropical electric field on the processes in the lower atmosphere and geomagnetic field configuration. Adv Space Res 64(10): 1854-1864. DOI: 10.1016/j.asr.2019.06.029.

Korenkov YuN, Klimenko VV, Forster M, Bessarab FS, Surotkin VA. 1998. Calculated and observed ionospheric parameters for Magion-2 passage above EISCAT on July 31 1990. J Geophys Res 103(A7): 14697-14710. DOI: 10.1029/98JA00210.

Korenkov YN, Klimenko VV, Klimenko MV, Bessarab FS, Korenkova NA, et al. 2012. The global thermospheric and ionospheric response to the 2008 minor sudden stratospheric warming event. J Geophys Res 117: A10309. DOI: 10.1029/ 2012JA018018.

Labitzke K, Kunze M. 2009. On the remarkable Arctic winter in 2008/2009. J Geophys Res 114: D00I02. DOI: 10.1029/ 2009JD012273. 
Liu H-L, Roble RG. 2002. A study of a self-generated stratospheric sudden warming and its mesospheric-lower thermospheric impacts using the coupled TIME-GCM/CCM3. J Geophys Res 107(D23): 4695. DOI: 10.1029/2001JD001533.

Liu H, Doornbos E, Yamamoto M, Tulasi Ram S. 2011. Strong thermospheric cooling during the 2009 major stratosphere warming. Geophys Res Lett 38: L12102. DOI: 10.1029/2011GL047898.

Liu H, Jin H, Miyoshi Y, Fujiwara H, Shinagawa H. 2013. Upper atmosphere response to stratosphere sudden warming: Local time and height dependence simulated by GAIA model. Geophys Res Lett 40: 635-640. DOI: 10.1002/grl.50146.

Liu H, Miyoshi Y, Miyahara S, Jin H, Fujiwara H, Shinagawa H. 2014. Thermal and dynamical changes of the zonal mean state of the thermosphere during the 2009 SSW: GAIA simulations. J Geophys Res 119: 6784-6791. DOI: 10.1002/2014JA020222.

Meraner K, Schmidt H. 2016. Transport of nitrogen oxides through the winter mesopause in HAMMONIA. J Geophys Res 121: 25562570. DOI: $10.1002 / 2015 J D 024136$.

Namgaladze AA, Korenkov YuN, Klimenko VV, Karpov IV, Bessarab FS, Surotkin VA, Glushenko TA, Naumova NM. 1988. Global model of the thermosphere-ionosphere-protonosphere system. Pure Appl Geophys (PAGEOPH) 127(2/3): 219254. DOI: 10.1007/978-3-0348-6532-6_3.

Pancheva D, Mukhtarov P. 2011. Stratospheric warmings: The atmosphere-ionosphere coupling paradigm. J Atmos Sol-Terr Phys 73(13): 1697-1702. DOI: 10.1016/j.jastp.2011.03.006.

Pedatella NM, Liu H-L. 2013. The influence of atmospheric tide and planetary wave variability during sudden stratosphere warmings on the low latitude ionosphere. J Geophys Res Space Phys 118: 5333-5347. DOI: 10.1002/jgra.50492.

Pedatella NM, Liu H-L, Richmond AD, Maute A, Fang T-W. 2012. Simulations of solar and lunar tidal variability in the mesosphere and lower thermosphere during sudden stratosphere warmings and their influence on the low-latitude ionosphere. J Geophys Res 117: A08326. DOI: 10.1029/2012JA017858.

Pedatella NM, Fang T-W, Jin H, Schmidt H, Chau JL, Siddiqui TA, Goncharenko L. 2016. Multimodel comparison of the ionosphere variability during the 2009 sudden stratosphere warming. J Geophys Res 121: 7204-7225. DOI: 10.1002/ 2016JA022859.

Pedatella NM, Liu H-L, Marsh DR, Raeder K, Anderson JL, Chau JL, Goncharenko LP, Siddiqui TA. 2018. Analysis and hindcast experiments of the 2009 sudden stratospheric warming in WACCMX+DART. J Geophys Res 123: 3131-3153. DOI: 10.1002/2017JA025107.

Schmidt H, Brasseur GP, Charron M, Manzini E, Giorgetta MA, Diehl T, Fomichev VI, Kinnison D, Marsh D, Walters S. 2006. The HAMMONIA chemistry climate model: Sensitivity of the mesopause region to the 11-year solar cycle and $\mathrm{CO}_{2}$ doubling. J Climate 19: 3903-3931. DOI: 10.1175/JCLI3829.1.

Singh RP, Pallamraju D. 2015. On the latitudinal distribution of mesospheric temperatures during sudden stratospheric warming events. J Geophys Res Space Phys 120: 2926-2939. DOI: 10.1002/2014JA020355.

Tan B, Chu X, Liu H-L, Yamashita C, Russell JM III. 2012. Zonalmean global teleconnection from 15 to $110 \mathrm{~km}$ derived from SABER and WACCM. J Geophys Res 117: D10106. DOI: 10.1029/2011JD016750.

Vasiliev PA, Bessarab FS, Karpov IV, Klimenko VV, Klimenko MV, Sukhodolov TV, Rozanov EV. 2019. Tidal and planetary waves in the lower thermosphere and ionosphere simulated with the EAGLE model for the January 2009 sudden stratospheric warming conditions. Izv Atmos Ocean Phys 55(2): 178-187. DOI: 10.1134/S0001433819020130.

Wang H, Fuller-Rowell TJ, Akmaev RA, Hu M, Kleist DT, Iredell MD. 2011. First simulations with a whole atmosphere data assimilation and forecast system: The January 2009 major sudden stratospheric warming. J Geophys Res 116: A12321. DOI: 10.1029/ 2011JA017081.

Yamazaki Y. 2014. Solar and lunar ionospheric electrodynamic effects during stratospheric sudden warmings. J Atmos Sol-Terr Phys 119: 138-146. DOI: 10.1016/j.jastp.2014.08.001.

Zakharenkova I, Astafyeva E, Cherniak I. 2016. GPS and GLONASS observations of large-scale traveling ionospheric disturbances during the 2015 St. Patrick's Day storm. J Geophys Res 121(12): 12,138-12,156. DOI: 10.1002/2016JA023332.

Cite this article as: Klimenko MV, Klimenko VV, Bessarab FS, Sukhodolov TV, Vasiliev PA, et al. 2019. Identification of the mechanisms responsible for anomalies in the tropical lower thermosphere/ionosphere caused by the January 2009 sudden stratospheric warming. J. Space Weather Space Clim. 9, A39. 